\title{
Hadley Cantril: A Pioneer in Public Opinion Research
}

\author{
Adrian J. Tomyn ${ }^{1}$
}

Published online: 10 October 2017

(C) Springer Science+Business Media B.V. and The International Society for Quality-of-Life Studies (ISQOLS) 2017

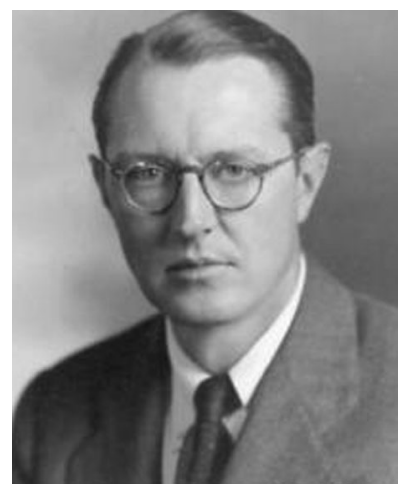

Born in Utah in 1906, Dr. Hadley Cantril was an American public opinion analyst and academic. He is perhaps most-remembered for developing the Cantril SelfAnchoring Striving Scale (Cantril 1965), also known as 'Cantril's Ladder' published in 'The pattern of Human Concerns'. Cantril's Ladder is a measurement instrument that asks people to rate their present, past, and anticipated future satisfaction with life on a scale anchored by their own identified values. In responding to this scale, people are presented with a ladder and steps numbered from 0 (representing their worst possible life) at the bottom to 10 (representing their best possible life) at the top. Respondents then indicate on which step they feel they personally stand. The Cantril Self-Anchoring Striving Scale has been used in many global surveys, most notably, Gallup's World Poll and Gallup's in-depth daily poll of America's wellbeing, spanning more than 150 countries and representing more than $98 \%$ of the world's population. 'The Patterns

Adrian J. Tomyn

adrian.tomyn@gmail.com

1 Deakin University, Melbourne, Australia 
of Human Concerns' would prove Cantril's most successful work, in a career spanning more than 100 published journal articles and 18 books.

Dr. Cantril attended Dartmouth College in Hanover, New Hampshire, receiving a Bachelor of Science Degree in 1928 and went on to earn his PhD from Harvard in 1931. In 1936, he accepted a position at the Princeton Psychology Department, for which he later became Chairman. In 1939, Cantril established the Princeton Listening Centre to study German radio propaganda. The following year he founded Princeton University's Office of Public Opinion Research. During this period, Cantril was a notable figure in combining survey research methods of commercial networks and those commonly employed within social psychology. This combined approach, in addition to segmentation of the population based on demographic characteristics into more clearly specified profiles, enabled researchers to better understand social trends with a much higher degree of precision than ever before.

Originally published in 1940, Cantril is also well known for his popular book 'The invasion from Mars: A study in the psychology of panic'. This book is based on a study that immediately followed Orson Welles broadcast radio adaptation of H. G. Wells' The War of the Worlds' (1898), which caused widespread panic in the United States when it aired on the radio shows Halloween episode of the series on Sunday, October 30, 1938. The book explored the impact of radio as a new communication media and how latent anxieties can lead to mass hysteria. Cantril's research suggested that the impact of the broadcast on frightened citizens had less to do with what went out live on air than with the standards of judgment that people did or did not use in evaluating what they were hearing.

Dr. Cantil died on May 28, 1969, at the age of 62 years. At this time, he was Chairman of the Board of the Institute for International Social Research, a position he had held since 1955. Dr. Cantril's contributions to psychology, politics and social indicators more broadly are best described by F.P Kilpatrick in Cantril and Cantril (1988).

“...psychology lost a scholar who embraced pioneering as a way of life, not because he wanted to be known as a pioneer, but because he's quest for increased understanding of human behaviour would not let him do otherwise. His extraordinary talent for recognizing new and fertile territory at the frontier, plowing it and demonstrating its productivity, and then moving on, resulted in major contributions in the psychology of propaganda; public opinion research; applications of psychology and psychological research to national policy, international understanding, and communication; developmental psychology; the psychology of social movements; measurement and scaling; humanistic psychology; the psychology of perception; and, basic to all of them, the analysis of human behaviour from the transactional point of view."

\section{References}

Cantril, H. (1940). The invasion from Mars: A study in the psychology of panic. Transaction Publishers: Piscataway.

Cantril, H. (1965). The pattern of human concerns. New Brunswick: Rutgers University Press.

Cantril, H., \& Cantril, A. H. (Eds.). (1988). Psychology, Humanism, and Scientific Inquiry: The Selected Essays of Hadley Cantril. Transaction Publishers: Piscataway. 